\title{
High prevalent human papillomavirus infections of the oral cavity of asymptomatic HIV-positive men
}

\author{
Rocío Méndez-Martínez ${ }^{1,2 \dagger}$, Silvia Maldonado-Frías ${ }^{3 \dagger}$, Salvador Vázquez-Vega ${ }^{4}$, Yanink Caro-Vega ${ }^{5}$, \\ José Guadalupe Rendón-Maldonado ${ }^{6}$, Miriam Guido-Jiménez ${ }^{7}$, Brenda Crabtree-Ramírez ${ }^{5}$, \\ Juan G. Sierra-Madero ${ }^{5}$ and Alejandro García-Carrancá ${ }^{7 *}$
}

\begin{abstract}
Background: Incidence of anal and oral infections with Human Papillomavirus (HPV) is increasing, particularly among Human Immunodeficiency Virus-positive (HIV+) men. HPV type 16 has exhibited the highest incidence and only limited data is available on other prevalent types, variants of HPV16, as well as associated factors. We were interested in identifying prevalent HPV types, variants of type 16, as well as factors associated with HPV16 infections in the oral cavity of HIV+ men who have sex with men (MSM).
\end{abstract}

Methods: A cross-sectional study of oral cavity samples from HIV+ MSM, that in a previous study were identified as positive for HPV16 in the anal canal. Cells from the oral cavity 102 samples, paired with 102 from the anal canal of same patient) were used to extract DNA and detect HPV infections using INNO-LiPA HPV Genotyping Extra II, and PCR. From these, 80 samples (paired, 40 anal and 40 oral) were used to identify variants of type 16 by sequencing. Statistical differences were estimated by the $X^{2}$ test, and $p$ values equal to or less than 0.05 were considered significant. SPSS ver. Twenty-four statistical software (IBM Corp) was used.

Results: We found a high prevalence of High-Risk HPV (HR-HPV) and Low-Risk HPV (LR-HPV). Patients were positive in the oral cavity for HR types; 16, 39 and 18 (80.4, 61.8 and 52.9\% respectively) and LR types 11 and 6 (53.9 and $34.3 \%$ respectively). Surprisingly, only European variants of type 16 were found in the oral cavity, although American Asian (22.5\%) and African (2.5\%) variants were identified in the anal canal. The analysis showed that CD4 counts could be the most important risk factor associated with HR-HPV infections in the oral cavity, anal canal or both anatomical regions. The risk of infection of the oral cavity with type 18 increased in men diagnosed with HIV for more than 6 years.

Conclusions: Prevalence of both HR and LR HPV's in the oral cavity of Mexican HIV+ MSM is very high. The fact that only European variants of HPV16 were found in the oral cavity suggest a possible tropism not previously described.

Keywords: HIV +, HPV, Types and variants MSM, Oral cavity, Anal canal

\footnotetext{
* Correspondence: carranca@biomedicas.unam.mx

${ }^{\dagger}$ Rocío Méndez-Martínez and Silvia Maldonado-Frías contributed equally to this work

${ }^{7}$ Unidad de Investigación Biomédica en Cáncer, Instituto de Investigaciones Biomédicas, Universidad Nacional Autónoma de México \& Instituto Nacional de Cancerología, Av. San Fernando \#22, Tlalpan, 2do piso, Torre de Investigación Básica, 14080, CDMX, México City, Mexico

Full list of author information is available at the end of the article
}

(c) The Author(s). 2020 Open Access This article is distributed under the terms of the Creative Commons Attribution 4.0 International License (http://creativecommons.org/licenses/by/4.0/), which permits unrestricted use, distribution, and reproduction in any medium, provided you give appropriate credit to the original author(s) and the source, provide a link to the Creative Commons license, and indicate if changes were made. The Creative Commons Public Domain Dedication waiver (http://creativecommons.org/publicdomain/zero/1.0/) applies to the data made available in this article, unless otherwise stated. 


\section{Background}

HPV's are recognized as one of the major causes of sexually transmitted infections related to cancer worldwide, and have been detected in cervical, anal and oral high-grade intraepithelial lesions [1-3]. Among them, HPV type 16 is the most common one, causing the majority of cervical and anogenital cancer as well as an important proportion of head and neck cancers [4-10]. Oral infection with HPV16, is associated with oropharyngeal cancer (OPC) and the oral sex play an important role in their acquisition $[11,12]$.

Infection with human immunodeficiency virus (HIV) affects 36.9 million people worldwide with more than 1.7 million persons in Latin America [13, 14]. HIV infections cause a marked decrease in host defenses, generating conditions for an increased rate of coinfections [15]. $\mathrm{HIV}+$ patients have a high risk of developing cancer due to coinfections by $\mathrm{HR}-\mathrm{HPV}[8,16]$. In particular, the presence of HPV16 is relevant since it is the major type associated to cancer in HIV+ patients [17-20]. The persistent oral infection of these patients have with HRHPV can lead to development of head and neck cancer (HNC), with a minor association with oral cancer and a major role with OPC [21-23].

The prevalence of oral HR-HPV infection is relatively low among the general population, accounting for 3.5\%, [24] while a higher prevalence of up to $50 \%$ has been reported among HIV + MSM, showing high vulnerability by coinfection in different anatomical regions [8, 21, 25]. Persistence of infections and progression to High grade Squamous Intraepithelial Lesion (HSIL) and cancer development have been are associated with variants of HPV16 [26-30].

Variants of HPV types reflect an evolutionary history of viral genomes associated with the rapid expansion of the human populations they infect and that can be used for epidemiological and etiologic studies to investigate to transmission of this virus within and among populations, as well as their presence on different anatomical regions. HPV16 variants have been grouped on five main groups: European (E), Asian (As), Asian American (AA), African-1 (Af1), African-2 (Af2), that show a particular geographic distribution, often clustering at specific parts of the world, such as Africa East Asia, North and Latin-America [31, 32]. Several studies have observed a high risk of cervical cancer associated with non-European variants of HPV-16. Infection with non-European variants increases the risk from 2 to 9 times for the development of cervical cancer [33, 34]. Studies conducted in Brazil [35] and the United States [29], are found that non-European variants are associated with persistent infection and that these variants are most frequent in HSIL $[29,36]$. On the other hand, Berumen et al. in 2001 found that the AA variants confer a higher risk for development of cervical cancer compared to variants European, and that about a quarter of cervical cancer cases in Mexico are attributed to these variants [33]. Similarly, Xi et al. in 2007, showed that women infected with the variants Af2 and AA have 2.7 (95\% CI 1.07.0) and 3.1 (95\% CI, 1.6-6.0) times higher risk of IAS 3 compared to Women infected with European variants [37].

Previously our group determined that HIV+ MSM exhibited a multiplicity of associated viral types, in addition to HPV16 in anal canal and among HPV16positive patients, European variants were the most prevalent [38]. We now aimed to determine the prevalence of HR and LR types of HPV in addition to type 16 and determine the nature of HPV16 variants, as well as clinical factors associated with HPV infections in the oral cavity of HIV+ MSM that are positive for HPV16 in the anal canal of same patients. In addition, the information on HPV prevalence and genotypes in Mexican $\mathrm{HIV}+$ patients are necessary for HPV related anal and oral neoplasia prevention.

\section{Methods \\ Samples}

Three hundred twenty-four patients were recruited in the HIV Clinic at Instituto Nacional de Ciencias Médicas y Nutrición "Salvador Zubirán” located in Mexico City. Selected samples have the characteristic of being positive for type 16 , determined in a previous study of the prevalence of HPV in the anal canal of HIV+ MSM [38].

In this cross-sectional study, we analysed 204 samples (102 HPV16+ in the anal canal and 102 paired from the oral cavity of the same patients) to detect simultaneous co-infections of other HPV types. From these, only 80 with an enough sample quantity, (paired 40 anal and 40 oral) were obtained and used to identify variants of type 16. Samples were obtained and processed as previously described by Mendez et al., 2014 [38].

\section{Data collection}

Socio-demographic, clinical and sexual behaviour information was collected using a self-applied written questionnaire. Clinical information was verified and completed with information available in the clinic records. The age of participants, education, employment, time since HIV diagnosis, time with anti-retroviral therapy treatment (time with ART), regimen of ART initiation (regimen of antiretroviral initiation), were asked. CD4 (cells $/ \mathrm{mm}^{3}$ ) levels, and viral suppression (defined as HIV-RNA <200 copies/ $\mathrm{ml})$, were evaluated.

\section{Typing HPV}

Extraction and purification of DNA was performed with the Genomics Wizard kit (PROMEGA; Madison, WI 53711-5399 USA). For identification of viral types present in the samples, we used the INNO-LiPA ${ }^{\bullet} \mathrm{HPV}$ Genotyping Extra II kit (INNOGENETICS Heiden 
Germany), which detects 32 different HPVs. HR-HPV $(16,18,31,33,35,39,45,51,52,56,58,59,66$ and 68$)$ and LR-HPV $(6,11,40,42,43,44,54,61,62,67,81,83$ and 89 ) and the additional types; 26, 53, 70, 73 and 82.

\section{Identification of HPV-16 variants}

The HPV16+ samples were subjected to a polymerase chain reaction (PCR) to identify variants within E6 and the long control region (LCR) with specific primers for HPV16 (5' GCAACAGTTACTGCGACGTG3'/5'GGACACAGT GGCTTTTGACA 3'; product size: $215 \mathrm{pb}$ for E6 and 5'TCAACCGAATTCGGTTGCAT3'/ 5'ACCTTTACACA GTTCATGTA3'; product size: $363 \mathrm{pb}$ ). The PCR products were sequenced using the Big Dye terminator kit and equipment Applied Biosystems 3500/3500xL Genetic Analyzer. Analysis of the sequences was done with the Chromas Program and the alignment of them program Multiple Sequence Alignment-Clustalw.

\section{Statistical analyses}

A descriptive statistical analysis was performed to summarize the sociodemographic characteristics of the selected population. The quantitative variables with normal distribution, were expressed as mean and standard deviations (SD). For data with free distribution, the median and Interquartile Ranges (IQR) were used. Qualitative variables were categorized and expressed by frequency and percentage. The prevalence of HPV was reported as the proportion of anal, oral and anal-oral samples positive for each identified viral type. (the positivity of the high risk and low risk HPV was considered when the proportion of positive cases of HPV in which the specific HPV was detected). The bivariate (Pearson's $\mathrm{X}^{2}$ test) and multivariate analysis (bivariate logistic regression) of risk factors (age, education, employment, time since HIV diagnosis, time with AntiRetroviral Treatment (ART), regimen of ART initiation, CD4 levels and viral suppression) were performed specifically for each type of HPV and as group: $\operatorname{LR} \operatorname{HPV}(6,11,40$, 44 and 70), and HR HPV (16, 18, 39, 51, 52, 66 and 68), HPV 16-18 and "Other HR HPV" (39, 51, 52, 66 and 68 that excluded the types 16 and 18). From the multivariate analysis adjusted for the risk factors, above mentioned, for infection by type of HPV (individual or in group), in the anatomical regions studied, those that had statistical significance for each logistic regression model were represented. For each variable, the alpha level used for the statistical analyses' significance was $p<0.05$. SPSS ver. Twenty-four statistical software (IBM Corp) was used.

\section{Results}

Sociodemographic characteristics of participants

One hundred two patients were included in the study. The age of participants ranged from 21 to 61 years, average was $38.4 \pm 8.0$ years. Median time since diagnosis of HIV was
4.3 years (range, $2.25-7.85$ years), while median of ART was 2.16 years (range, $0.33-4.93$ years); $59.8 \%$ of participants have an ART with a regimen based Non-Nucleotide Reverse Transcriptase Inhibition (NNRTIs). On average, the CD4 count was $428.76 \pm 236.23$, and nearly $80 \%$ of the participants reported viral suppression (Table 1).

\section{Prevalence of LR \& HR HPV in the oral cavity}

We detected 5 LR types; 6, 11, 40, 44 and 70, and 7 HR types; $16,18,39,51,52,66$ and 68 . HPV11 was the most

Table 1 Sociodemographic characteristics from the 102 participants in this study

\begin{tabular}{|c|c|c|c|c|}
\hline Variable & $N$ & $(\%)$ & MCT & DM \\
\hline Age (years)) & & & 38.43 & \pm 8.0 \\
\hline$\leq 35$ & 37 & 36.3 & & \\
\hline $36-41$ & 30 & 29.4 & & \\
\hline$\geq 42$ & 35 & 34.3 & & \\
\hline Education (years) & & & 12 & $(11.63-12.00)$ \\
\hline$\leq 12$ & 57 & 55.9 & & \\
\hline$\geq 13$ & 45 & 44.1 & & \\
\hline \multicolumn{5}{|l|}{ Employment } \\
\hline No & 31 & 30.4 & & \\
\hline Yes & 71 & 69.6 & & \\
\hline \multicolumn{2}{|c|}{ Time since HIV diagnosis (years) } & & 4.3 & $(2.25-7.85)$ \\
\hline$\leq 3.16$ & 34 & 33.3 & & \\
\hline $3.17-6.17$ & 33 & 32.4 & & \\
\hline$\geq 6.18$ & 35 & 34.3 & & \\
\hline Time with ART (years) & & & 2.16 & $(0.33-4.93)$ \\
\hline$\leq 0.65$ & 36 & 35.3 & & \\
\hline $0.66-4.0$ & 31 & 30.4 & & \\
\hline$\geq 4.1$ & 35 & 34.3 & & \\
\hline \multicolumn{5}{|l|}{ Regimen of ART } \\
\hline NNRTIS & 61 & 59.8 & & \\
\hline $\mathrm{Pl}$ & 33 & 32.4 & & \\
\hline Other & 8 & 7.8 & & \\
\hline CD4 count & & & 428.76 & \pm 236.23 \\
\hline$\leq 200$ & 18 & 17.6 & & \\
\hline $201-499$ & 53 & 52 & & \\
\hline$\geq 500$ & 31 & 30.4 & & \\
\hline \multicolumn{5}{|l|}{ Viral suppression } \\
\hline No & 21 & 20.6 & & \\
\hline Yes & 81 & 79.4 & & \\
\hline
\end{tabular}

Note: *MCT Measure of central tendency and DM Dispersion measure (Mean \pm Deviation Standard Deviation [SD] or Median and Inter Quartile Range ([IQR] = $\left.\mathrm{P}^{\circ} 25-\mathrm{P}^{\circ} 75\right)$ were reported for continuous variables. $\mathrm{N}=$ Frequency. $(\%)=$ Percentage reported for categorical variables. Time with ART = Time with antiretroviral therapy treatment. Regimen of ART initiation = Regimen of antiretroviral initiation. NNRTIs: Non-Nucleoside Reverse Transcriptase Inhibition. PI: Protease inhibitor. Viral suppression defined as HIV-RNA $<200$ copies $/ \mathrm{mL}$. (Bavinton et al., 2018) 
prevalent LR type; $65.7 \%$ (67 patients) in the anal canal and $53.9 \%$ (55 patients) in the oral cavity, while $37.3 \%$ (38 patients) exhibited type 11 in both regions.

Regarding HR HPV, HPV16 was the most prevalent type of HR-HPV type in the oral cavity with $80.4 \%$ (82 patients). HPV39 was the second most prevalent HR type; $58.8 \%$ (60 patients) in the anal canal and 61.8\% (63 patients) in the oral cavity, while $33.3 \%$ (34 patients) exhibited it in both regions.

HPV52 type was the third; $56.9 \%$ (58 patients) in the anal canal and $49 \%$ (50 patients) in the oral cavity, while $26.5 \%$ (27 patients) in both regions. The rest of HR-HPV types $(18,51,66$, and 68$)$ were less prevalent in anal canal, oral cavity or both anatomical regions.

Considering LR types, while $80.4 \%(82 / 102)$ of the anal samples were positive, only $66.7 \%(68 / 102)$ of the oral samples contained LR HPV. The positivity for LR in both anatomical regions was 55.9\% (57/102) (Fig. 1).

HPV 16-18 were present almost equal in anal and oral cavity (45.1 and 50.0\%, respectively) and in $21.6 \%$ in both anatomical sites. The group of "Other HR HPV" (HPVs 39, 51, 52, 66 and 68) showed high prevalence in the samples from the anal canal, oral cavity and simultaneously in both anatomical regions (92.2 and 80.4\% and $72.5 \%$, respectively) (Table 2 ).

\section{Risk factors associated with HPV infections in the anal} canal, the oral cavity, and both sites

To evaluate the possible association of several risk factors with or without probability of HPV infection, we
Table 2 Prevalence of different HPV in the anal canal, the oral cavity, or both anatomical regions

\begin{tabular}{|c|c|c|c|c|c|c|}
\hline \multirow[t]{2}{*}{ Viral type } & \multicolumn{2}{|c|}{ Anal canal } & \multicolumn{2}{|c|}{ Oral cavity } & \multicolumn{2}{|l|}{ Both } \\
\hline & $\%$ & $\mathrm{~N}$ & $\%$ & $\mathrm{n}$ & $\%$ & $\mathrm{~N}$ \\
\hline \multicolumn{7}{|l|}{ Low-risk HPV types } \\
\hline 6 & 39.2 & 40 & 34.3 & 35 & 14.7 & 15 \\
\hline 11 & 65.7 & 67 & 53.9 & 55 & 37.3 & 38 \\
\hline 40 & 1 & 1 & 0 & 0 & 0 & 0 \\
\hline 44 & 0 & 0 & 1 & 1 & 0 & 0 \\
\hline 70 & 14.7 & 15 & 3.9 & 4 & 2 & 2 \\
\hline LR-HPV & 80.4 & 82 & 66.7 & 68 & 55.9 & 57 \\
\hline \multicolumn{7}{|c|}{ High-risk HPV types } \\
\hline 16 & 100.0 & 102.0 & 80.4 & 82 & 80.4 & 82 \\
\hline 18 & 50.0 & 51 & 52.9 & 54 & 27.5 & 28 \\
\hline 39 & 58.8 & 60 & 61.8 & 63 & 33.3 & 34 \\
\hline 51 & 44.1 & 45 & 38.2 & 39 & 18.6 & 19 \\
\hline 52 & 56.9 & 58 & 49.0 & 50 & 26.5 & 27 \\
\hline 66 & 49.0 & 50 & 33.3 & 34 & 16.7 & 17 \\
\hline 68 & 18.6 & 19 & 13.7 & 14 & 4.9 & 5 \\
\hline HPV16-18 & 45.1 & 46 & 50.0 & 51 & 21.6 & 22 \\
\hline Other HR HPV & 92.2 & 94 & 80.4 & 82 & 72.5 & 74 \\
\hline
\end{tabular}

$\mathrm{LR} \mathrm{HPV}=6,11,40,44$ and 70 types. HPV 16-18 = includes both HPV types Other HR HPV $=39,51,52,66$ and 68 , and excluding types 16 and 18

performed a logistic regression adjusted by age of participants, education, employment, time since HIV diagnosis, time with anti-retroviral therapy treatment (time with ART), regimen of ART initiation (regimen of antiretroviral initiation), CD4 (cells $/ \mathrm{mm}^{3}$ ) levels, and viral

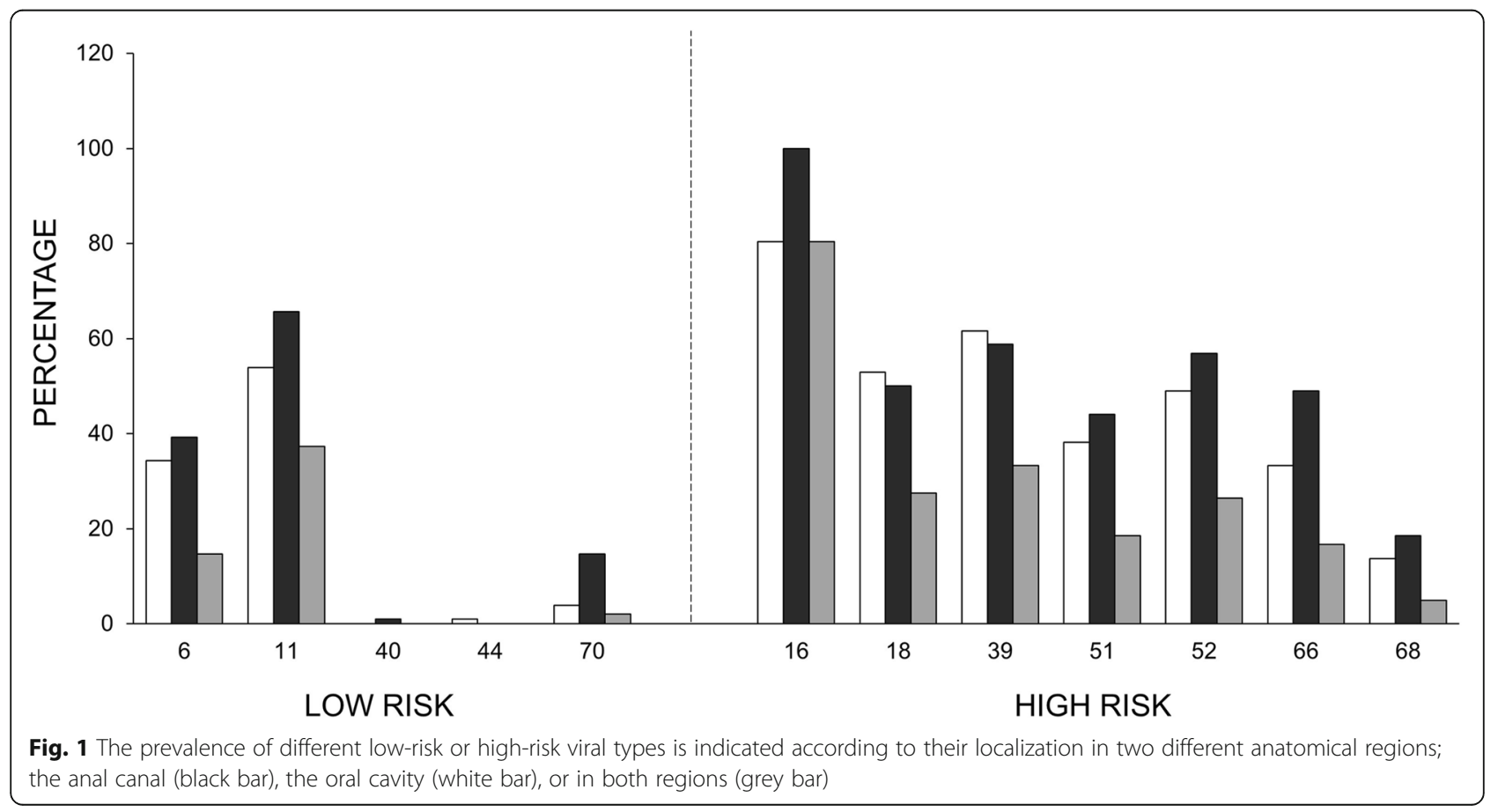


suppression (defined as HIV-RNA <200 copies/ml). Only those risk factors that had statistical significance for each logistic regression model are shown in Table 3.

Concerning HR HPV types, in oral infection with HPV 68 type was associated with time under ART treatment (6 months and a half to 4 years), while HPV 68 infection in the same anatomical region was less associated in patients older than 42 years.

In general, the risk of infection of the oral cavity with 66 and 51 types increases with CD4 counts between 201 and 499. Whereas oral infection with 66 type correlates with age (36-41 years). We found that the risk of infection of the oral cavity with type 18 increased in men diagnosed with HIV for more than 6 years. HPV 52 infection at both anatomical regions in men with CD4 (201-499) and without viral suppression was associated. The "Other HR types" infection risk was high associated in patients with CD4 counts between 201 and 499. On the contrary, HPV 39 infection in both anatomical sites (anal \& oral) in patients with CD4 $<200$ was low associated. Regarding HPV 6 infection was related in the anal region among men with lower education (fewer than 12 years), while oral infection with this same viral type was low linked in patients with a CD4 count $<200$. The HPV
70 infection in the anal region was less probable in patients under NNRTIs treatment regimen. The LR-HPV infection (as a group) were correlated in the oral-anal region of men who had work (Table 3).

\section{Identification of variants of HPV16}

From 204 samples (102 HPV16+ in the anal canal and 102 paired from the oral cavity of same patients), only 80 with enough sample quantity, (40 anal and 40 paired oral) were obtained and used to identify variants of type 16. Sequence analysis of PCR products from the E6 and LCR regions of type 16-positive samples showed three types of variants (European; E, Asian-American; AA, and African; Af) were present in the anal samples. The most frequent variant was European (75\%/30 patients), followed by Asian- American (22.5\%/9 patients), and African (2.5\%/1 patient). Surprisingly, in the oral cavity only European variants were detected (Fig. 2). The analysis of European variants vs Asian-American variants, and African variants, indicated this is not statistically significant (data not shown).

In the anal canal, the European Prototype (EP) was the most prevalent variant of HPV16 (13 patients), followed by EA176G (six patients), EC188G (five patients), EA178T

Table 3 Risk factors associated with low- and high-risk HPV in a Mexican MSM HIV+ population

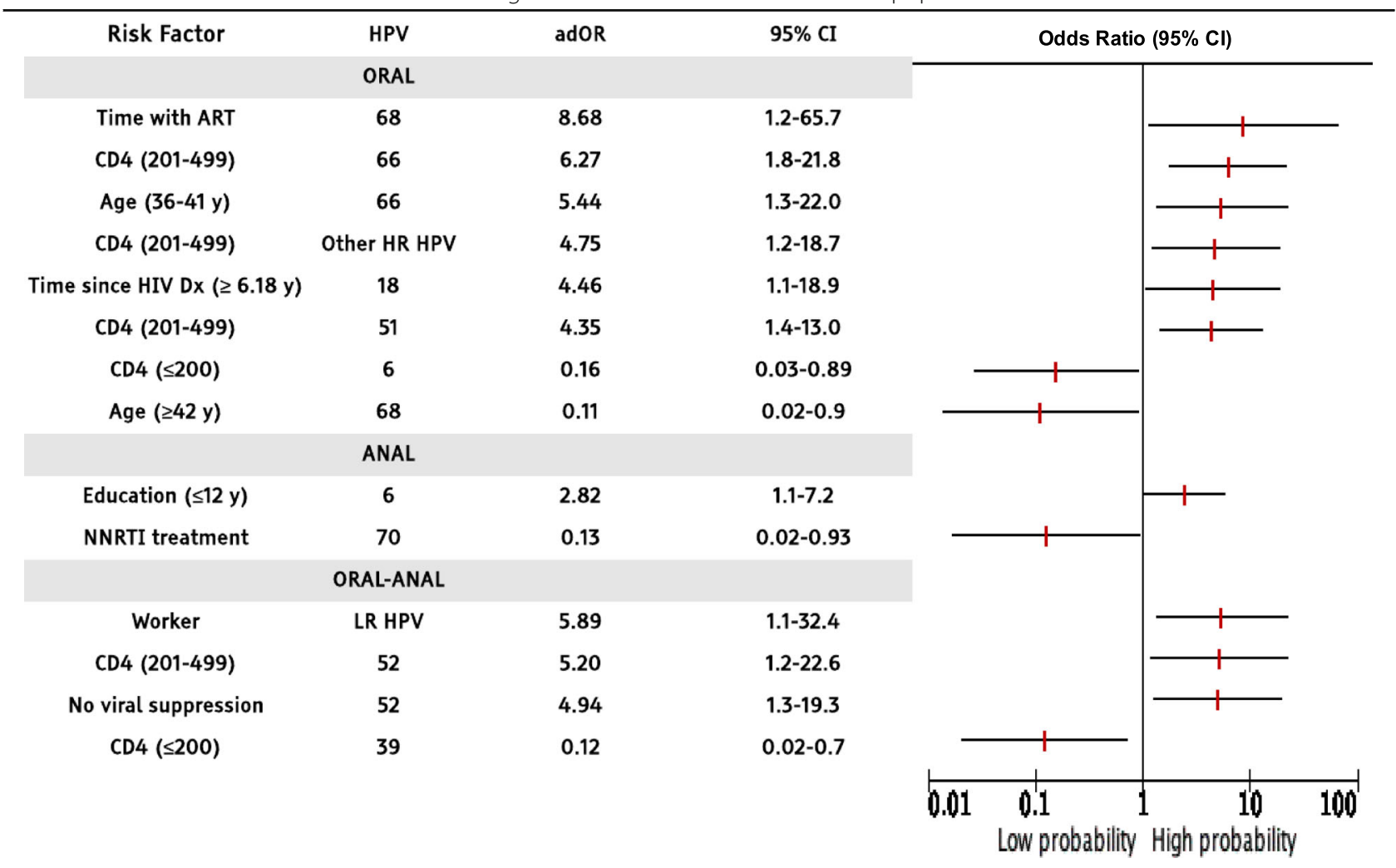

Note: Odds Ratios were adjusted (adOR) for all the variables included in this study [age of participants, education, employment, time since HIV diagnosis, time with anti-retroviral therapy treatment (time with ART), regimen of ART initiation (regimen of anti-retroviral initiation), CD4 (cells/mm ${ }^{3}$ ) levels, and viral suppression (defined as HIV-RNA $<200$ copies/ml)]. Only those risk factors that had statistical significance $(p<0.05)$ for each logistic regression model are presented in the table (even confidence intervals were ample in some instances, they were included if significant). $95 \%$ Confidence Intervals ( $95 \% \mathrm{Cl}$ ) 


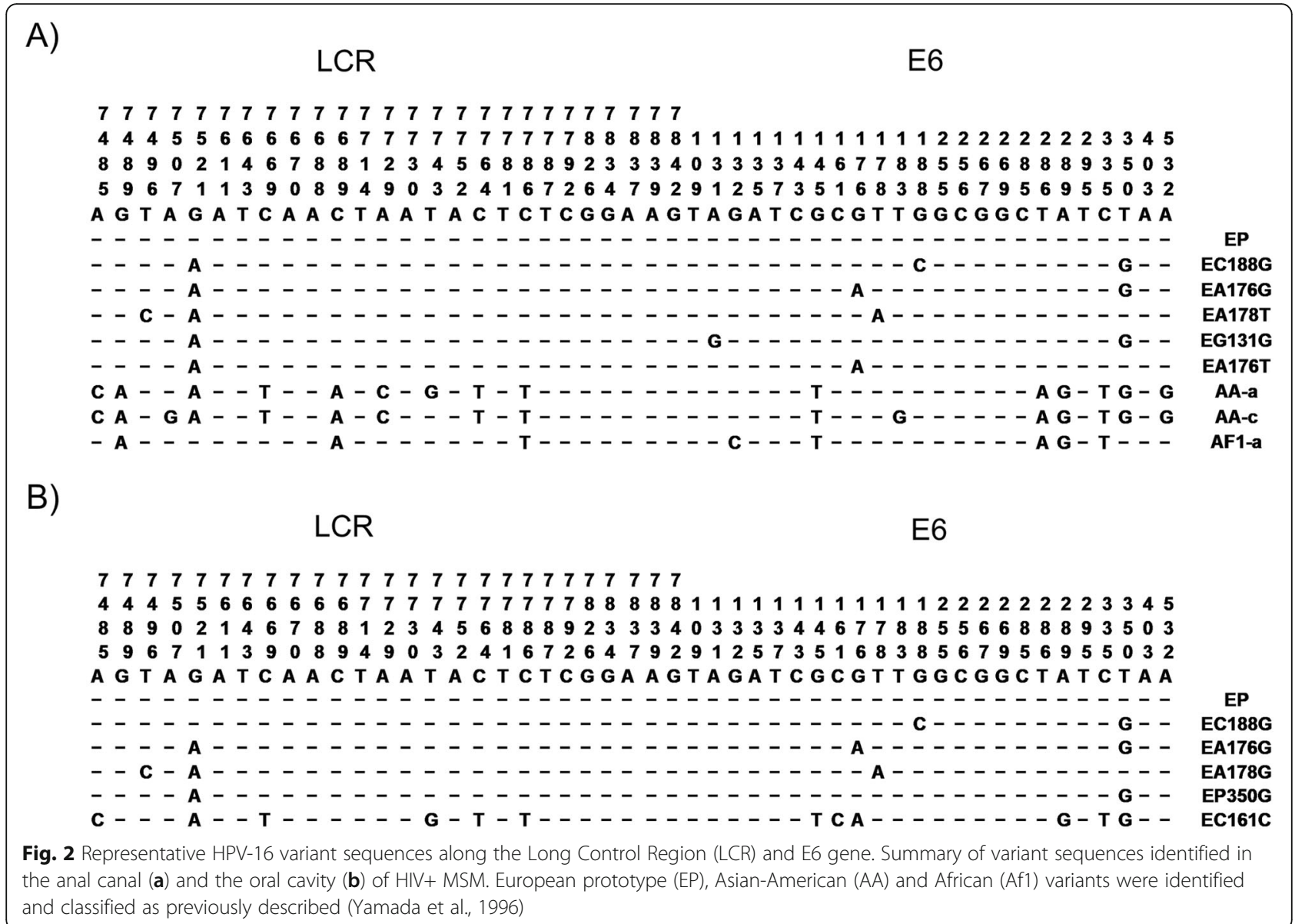

(three patients), and EG131G (two patients). Regarding non-European variants, the American-Asian AA-a (six patients) and AA-c (three patients) and the African Af1-a (one patient) were the most prevalent ones. In the oral cavity, the most prevalent variant of type 16 was the European 350G (18 patients), followed by the European Prototype (EP) (15 patients), EA176G (three patients), and EA178G and EC161G (Fig. 3a and b). Only 20\% (eight patients) had the same variant in both regions: five patients presented the European-variant Prototype in both regions, two patients presented the EC188G variant in both regions, and one patient presented the EA176G variant in both anatomical regions.

\section{Discussion}

HPV plays a decisive role in the development of anal, cervical squamous cell and oropharyngeal cancer; the most prevalent HPV types associated with these cancer and precancerous lesions is HPV16. Although several studies show multiple infection of HPV present in the anal canal $[8,20,27,38-41]$, the relationship of theses viral types in the oral cavity is unclear, reports suggest that oral HPV infection in MSM, differs from anogenital HPV infection $[39,40]$. This study investigated for the first time the multiple infection of HPV in the anal canal and the oral cavity of HPV16+ and HIV+ MSM of same patients.

The mechanisms of anal HPV infection are possibly due to both, sexual and not sexual transmission. The sexual transmission shown specific risk factors for anal HPV infection including younger age patients HIV+, and not sexual transmission includes insertion of transiently infected fingers or toys, as well as shedding from other infected genital sites [42-45]. On the other hands, recently is suggested that HPV infections in the oral cavity also are associated with sexual practices, however evidences show that vertical transmission is present in newborns from HPV + mothers, indicating that HPV can be acquired at an early age and may remain latent for years, and has been report that exists horizontal transmission, which can mediated by saliva [46]. It has been show that, the infection by HPV in oral cavity has higher prevalence by 16 type in young healthy and HIV+ men [47-49].

This cross-sectional study, from HIV+ Mexican MSM patients, showed that around two-thirds of these patients had both anal and oral infection with oncogenic HPV types We observed a high prevalence of HPV coinfections in the anal canal, confirming our previous report [38]. We found in the anal canal, that type 16 was the 


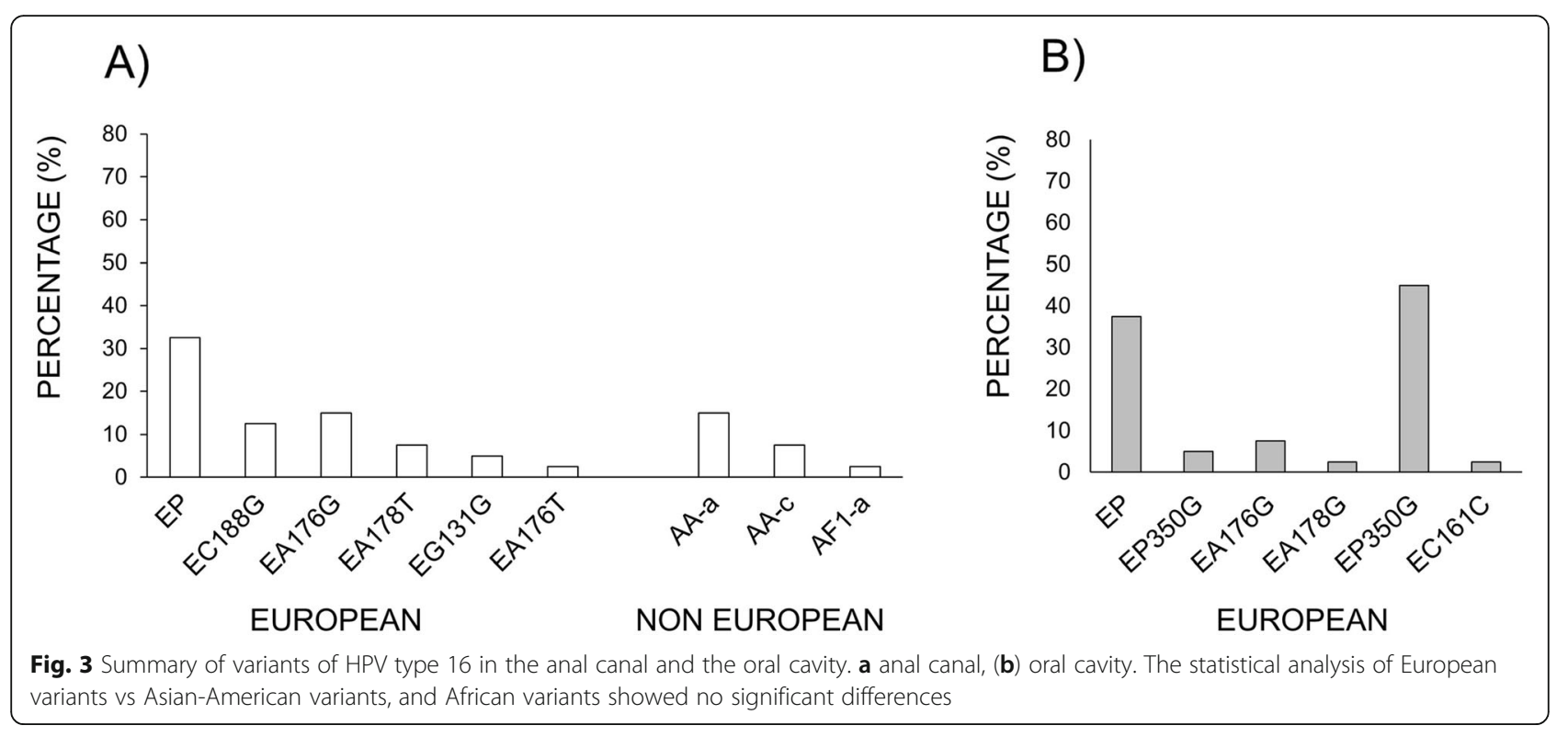

most prevalent, followed by type 39 . Type 16 predominated in the oral cavity too. We found a similar prevalence of co-infections with LR and HR types of HPV in our study, as compared to previously published work [50, 52]. Prevalence of types $16 / 18$ was similar to what has been shown in previous studies of patients in Europe and Western countries among HIV+ men [53]. Compared with heterosexual men (HM), the prevalence of HPV infection was much higher $[54,55]$.

Risk factors analysis showed that CD4 (201-499) count could be the most important risk factor associated with infection of oncogenic HPV types, in the oral cavity, anal region or both anatomical regions, (e.g. HPV66, 52 and 51), we found that anal and oral infection with oncogenic HPV types were significantly associated with decreased CD4 counts and short HAART durations. HPV infection can cause significant pathology in all men, but MSM are at particularly susceptible.

On other hand it has been widely reported that variants of viral types determined among human populations correlate with geographic regions, and associated with different pathologic risks for the development of cancerous lesions [29, 33, 35, 37]. Although we observed a high prevalence of European variants of type 16 in the anal canal, we found only European variant in the oral cavity. It is important to note that tropism for these different anatomical regions is suggested. The involvement of HPV16 variants in the determination of the persistence and progression of viral infection can be explained by the fact that nucleotide variations in the HPV coding region could result in a decrease in the immunogenicity of viral proteins, favoring the persistence of infection in immunocompetent individuals. In fact, the evaluation of the integration of HPV16 in the host genome seems to be a good biomarker for predicting anal precancerous lesions in HIV positive men [34]. The presence of the EP350G variant in both anatomical regions could suggest an infection by the same virus. It is worth nothing that this variant is related to persistence, fundamental for the development of HPV-related cancer. It would be very important to follow-up in this high-risk population as well as to implement a program for their vaccination.

\section{Conclusions}

In this study we found a high prevalence of HR and LR types of HPV, in addition to type 16 in the anal canal and the oral cavity of HIV+ MSM. Importantly, the fact that non-European variants of HPV16 were only found in the oral cavity suggests a tropism for different anatomical regions. In addition, the information on HPV prevalence and genotypes in asymptomatic Mexican HIV+ patients are necessary for HPV related anal and oral neoplasia prevention.

This finding supporting the importance of early prophylactic vaccination in this population to achieve maximum benefit. It is important to mention that the use of quadrivalent HPV (types 6,11,16,18) vaccine in HPV + MSM prevented $95 \%$ of persistence anal HPV infections in young HIV-uninfected MSM [56]. Because the HPV vaccine appears to be safe in HIV+ men, a significant proportion of HIV + MSM in Mexico may potentially benefit from the vaccine, which might prevent $\mathrm{HPV}$-associated anal or oral cancer.

Our data also support the need for establishing anal and oral screening systems for early detection of cancer among these patients and regular follow-up strategies, especially in HIV+ patients with high-risk HPV. Priority should be given to the identification and treatment of anal or oral lesions in MSM with HIV/AIDS. 


\section{Abbreviations}

ART: Anti-Retroviral Therapy; Cl: Confidence Intervals; DNA: Deoxyribonucleic acid; HAART: Highly Active Antiretroviral therapy; HIV + : Human Immunodeficiency Virus-positive; HM: Heterosexual men; HNC: Head and Neck Cancer; HPV: Human Papilloma Viruses; HR: High Risk; HSIL: High grade Squamous Intraepithelial Lesion; IQR: Interquartile Ranges; LCR: Long Control Region; LR: Low Risk; MSM: Men who have Sex with Men; NNRTIs: NonNucleotide Reverse Transcriptase Inhibition; OPC: Oropharyngeal cancer; OR: Odds Ratios; PCR: Polymerase chain reaction; PI: Protease Inhibitor; SD: Standard deviations

\section{Acknowledgements}

We thank MC. Patricia de la Torre (Instituto de Investigaciones BiomédicasUNAM) for her support in the sequencing of the samples.

\section{Authors' contributions}

RM-M processed samples for PCR, obtained results, analyzed them, and prepared the initial drafts of the manuscript. SM-F processed samples for $\mathrm{PCR}$, obtained results, prepared initial drafts of the manuscript, and corrected the latter. YC-V and SV-V performed the statistical analyses of the data and preparation of the manuscript and its corrections. MG-J processed the samples and participated in the preparation of the manuscript and in corrections. BC-R and JGS-M conduct clinical evaluations and obtained samples and data from the patients. JGR-M contributed to the elaboration of the manuscript and its corrections. AG-C designed the study, analyzed the results, corrected the manuscript, and provided support for the trial. All authors read and approved the final version of the manuscript.

\section{Funding}

Funds for this research were provided by Programa de Apoyo a Proyectos de Investigación e Innovación Tecnológica, from Dirección General de Asuntos del Personal Académico from Universidad Nacional Autónoma de México (PAPIIT-IN213016, to AG-C) and from Instituto Nacional de Cancerología, México. These entities only provide financial support for projects submitted by the authors.

\section{Availability of data and materials}

The datasets used and/or analyzed during the current study are available from the corresponding author on request. The sequencing data generated in this study has been deposited in the NCBI SRA database Accession: PRJNA591936; ID: 591936) (https://www.ncbi.nlm.nih.gov/bioproject/PRJNA5 91936).

\section{Ethics approval and consent to participate}

This study was approved by the Research and Ethics Committees from Instituto Nacional de Cancerología (INCan-Cl009/006/IBI) approved the study, as did the Institutional Committee of Biomedical Research in Humans from Instituto Nacional de Ciencias Médicas y Nutrición Salvador Zubirán (REF. INF-2166-17/17-1), and written informed consent was obtained from all participants to the study.

\section{Consent for publication}

Not applicable.

\section{Competing interests}

The authors declare that they have no competing interests.

\section{Author details}

'División de Investigación Básica, Instituto Nacional de Cancerología, Av. San Fernando \#22, Tlalpan, 2do piso, Torre de Investigación Básica, 14080, CDMX, México City, Mexico. ${ }^{2}$ Doctorado en Biotecnología \& Doctorado en Ciencias Biomédicas, Facultad de Ciencias Químico-Biológicas, Universidad Autónoma de Sinaloa, Culiacán, Sinaloa, Mexico. ${ }^{3}$ División de Estudios de Posgrado e Investigación, Facultad de Odontología, Universidad Nacional Autónoma de México, Universidad 3000, Coyoacán, Copilco Universidad, 04360 Ciudad de México, CDMX, México City, Mexico. ${ }^{4}$ Unidad de Investigación Epidemiológica y en Servicios de Salud, Centro Médico Nacional Siglo XXI, Instituto Mexicano del Seguro Social, Av. Doctores 330, Cuauhtemoc, 06720 Ciudad de México, CDMX, Mexico. ${ }^{5}$ Instituto Nacional de Ciencias Médicas y Nutrición "Salvador Zubirán" (INCMNSZ), Secretaría de Salud, México City, Mexico. ${ }^{6}$ Facultad de Ciencias Químico-Biológicas- UAS, Universidad
Autónoma de Sinaloa, Calz. de las Américas Norte 2771, Burócrata, 80030 Culiacán, Sinaloa, Mexico. ${ }^{7}$ Unidad de Investigación Biomédica en Cáncer, Instituto de Investigaciones Biomédicas, Universidad Nacional Autónoma de México \& Instituto Nacional de Cancerología, Av. San Fernando \#22, Tlalpan, 2do piso, Torre de Investigación Básica, 14080, CDMX, México City, Mexico.

Received: 1 July 2019 Accepted: 29 November 2019

Published online: 10 January 2020

\section{References}

1. Clifford GM, Smith JS, Aguado T, Franceschi S. Comparison of HPV type distribution in high-grade cervical lesions and cervical cancer: a metaanalysis. Br J Cancer. 2003:89:101-5.

2. Wong AK, Chan RC, Aggarwal N, Singh MK, Nichols WS, Bose S. Human papillomavirus genotypes in anal intraepithelial neoplasia and anal carcinoma as detected in tissue biopsies. Mod Pathol Off J U S Can Acad Pathol Inc. 2010;23:144-50.

3. Gillison ML, Koch WM, Capone RB, Spafford M, Westra WH, Wu L, et al. Evidence for a causal association between human papillomavirus and a subset of head and neck cancers. J Natl Cancer Inst. 2000;92:709-20.

4. Ripabelli G, Grasso GM, Del Riccio I, Tamburro M, Sammarco ML. Prevalence and genotype identification of human papillomavirus in women undergoing voluntary cervical cancer screening in Molise, Central Italy. Cancer Epidemiol. 2010;34:162-7.

5. Schiffman M, Doorbar J, Wentzensen N, de Sanjosé S, Fakhry C, Monk BJ, et al. Carcinogenic human papillomavirus infection. Nat Rev Dis Primer. 2016;2:16086.

6. Bosch FX, Broker TR, Forman D, Moscicki A-B, Gillison ML, Doorbar J, et al. Comprehensive control of human papillomavirus infections and related diseases. Vaccine. 2013;31(Suppl 7):H1-31.

7. zur Hausen H. Papillomaviruses causing cancer: evasion from host-cell control in early events in carcinogenesis. J Natl Cancer Inst. 2000;92:690-8.

8. Ucciferri C, Tamburro M, Falasca K, Sammarco ML, Ripabelli G, Vecchiet J. Prevalence of anal, oral, penile and urethral human papillomavirus in HIV infected and HIV uninfected men who have sex with men. J Med Virol. 2018;90:358-66.

9. Bosch FX, Manos MM, Muñoz N, Sherman M, Jansen AM, Peto J, et al. Prevalence of human papillomavirus in cervical cancer: a worldwide perspective. International biological study on cervical cancer (IBSCC) study group. J Natl Cancer Inst. 1995;87:796-802.

10. zur Hausen $\mathrm{H}$. Molecular pathogenesis of cancer of the cervix and its causation by specific human papillomavirus types. Curr Top Microbiol Immunol. 1994;186:131-56.

11. Donà MG, Spriano G, Pichi B, Rollo F, Laquintana V, Covello R, et al. Human papillomavirus infection and p16 overexpression in oropharyngeal squamous cell carcinoma: a case series from 2010 to 2014. Future Microbiol. 2015;10:1283-91.

12. Saulle R, Semyonov L, Mannocci A, Careri A, Saburri F, Ottolenghi L, et al. Human papillomavirus and cancerous diseases of the head and neck: a systematic review and meta-analysis. Oral Dis. 2015;21:417-31.

13. AIDSinfo | UNAIDS. http://aidsinfo.unaids.org/. Accessed 29 Jan 2019.

14. Global HIV \& AIDS statistics 2018 fact sheet. http://www.unaids.org/en/ resources/fact-sheet. Accessed 29 Jan 2019.

15. Wang C-CJ, Sparano J, Palefsky JM. Human immunodeficiency virus/ AIDS, human papillomavirus, and anal Cancer. Surg Oncol Clin N Am. 2017;26:17-31.

16. Engels EA, Yanik EL, Wheeler W, Gill MJ, Shiels MS, Dubrow R, et al. Cancerattributable mortality among people with treated human immunodeficiency virus infection in North America. Clin Infect Dis Off Publ Infect Dis Soc Am. 2017;65:636-43.

17. Mitra S, Crane L. Diagnosis, treatment, and prevention of anal cancer. Curr Infect Dis Rep. 2012;14:61-6.

18. Hanisch RA, Cherne SL, Sow PS, Winer RL, Hughes JP, Feng Q, et al. Human papillomavirus type 16 viral load in relation to HIV infection, cervical neoplasia and cancer in Senegal. Cancer Epidemiol. 2014;38:369-75.

19. Karbalaie Niya MH, Keyvani H, Safarnezhad Tameshkel F, Salehi-Vaziri M, Teaghinezhad-S S, Bokharaei Salim F, et al. Human papillomavirus type 16 integration analysis by real-time PCR assay in associated cancers. Transl Oncol. 2018;11:593-8.

20. Rovelli C, Poli A, Galli L, Cernuschi M, Tamburini AM, Racca S, et al. Presence of multiple genotypes in subjects with HPV-16 infection is highly associated 
with anal squamous intraepithelial lesions in HIV-1 infected males. PLoS One. 2017:12:e0186367.

21. Mooij SH, Boot HJ, Speksnijder AGCL, Stolte IG, Meijer CJLM, Snijders PJF, et al. Oral human papillomavirus infection in HIV-negative and HIV-infected MSM. AIDS Lond Engl. 2013;27:2117-28.

22. Castellsagué X, Alemany L, Quer M, Halec G, Quirós B, Tous S, et al. HPV Involvement in Head and Neck Cancers: Comprehensive Assessment of Biomarkers in 3680 Patients. J Natl Cancer Inst. 2016;108:djv403.

23. International Agency for Research on Cancer, editor. IARC monographs on the evaluation of carcinogenic risks to humans, volume 90 , Human papillomaviruses: this publication represents the views and expert opinions of an IARC Working Group on the Evaluation of Carcinogenic Risks to Humans, which met in Lyon, 15-22 February 2005. Lyon: IARC; 2007.

24. Chung CH, Bagheri A, D'Souza G. Epidemiology of oral human papillomavirus infection. Oral Oncol. 2014;50:364-9.

25. Beachler DC, Weber KM, Margolick JB, Strickler HD, Cranston RD, Burk RD, et al. Risk factors for oral HPV infection among a high prevalence population of HIV-positive and at-risk HIV-negative adults. Cancer Epidemiol Biomark Prev Publ Am Assoc Cancer Res Cosponsored Am Soc Prev Oncol. 2012;21:122-33.

26. Londesborough P, Ho L, Terry G, Cuzick J, Wheeler C, Singer A. Human papillomavirus genotype as a predictor of persistence and development of high-grade lesions in women with minor cervical abnormalities. Int J Cancer. 1996;69:364-8.

27. Xi LF, Critchlow CW, Wheeler CM, Koutsky LA, Galloway DA, Kuypers J, et al, Risk of anal carcinoma in situ in relation to human papillomavirus type 16 variants. Cancer Res. 1998:58:3839-44.

28. Xi LF, Demers GW, Koutsky LA, Kiviat NB, Kuypers J, Watts DH, et al. Analysis of human papillomavirus type 16 variants indicates establishment of persistent infection. J Infect Dis. 1995;172:747-55.

29. Xi LF, Koutsky LA, Galloway DA, Kuypers J, Hughes JP, Wheeler CM, et al. Genomic variation of human papillomavirus type 16 and risk for high grade cervical intraepithelial neoplasia. J Natl Cancer Inst. 1997;89:796-802.

30. Zehbe I, Voglino G, Delius H, Wilander E, Tommasino M. Risk of cervical cancer and geographical variations of human papillomavirus 16 E6 polymorphisms. Lancet Lond Engl. 1998;352:1441-2.

31. Xi LF, Kiviat NB, Hildesheim A, Galloway DA, Wheeler CM, Ho J, et al. Human papillomavirus type 16 and 18 variants: race-related distribution and persistence. J Natl Cancer Inst. 2006;98:1045-52.

32. Ho L, Chan SY, Burk RD, Das BC, Fujinaga K, Icenogle JP, et al. The genetic drift of human papillomavirus type 16 is a means of reconstructing prehistoric viral spread and the movement of ancient human populations. J Virol. 1993;67:6413-23.

33. Berumen J, Ordoñez RM, Lazcano E, Salmeron J, Galvan SC, Estrada RA, et al. Asian-American variants of human papillomavirus 16 and risk for cervical cancer: a case-control study. J Natl Cancer Inst. 2001;93:1325-30.

34. Xi LF, Carter JJ, Galloway DA, Kuypers J, Hughes JP, Lee SK, et al. Acquisition and natural history of human papillomavirus type 16 variant infection among a cohort of female university students. Cancer Epidemiol Biomark Prev Publ Am Assoc Cancer Res Cosponsored Am Soc Prev Oncol. 2002;11:343-51.

35. Villa LL, Sichero L, Rahal P, Caballero O, Ferenczy A, Rohan T, et al. Molecular variants of human papillomavirus types 16 and 18 preferentially associated with cervical neoplasia. J Gen Virol. 2000;81(Pt 12):2959-68.

36. Tabora N, Melchers WJG, van Doorn L-J, Quint W, Ferrera A. Molecular variants of HPV type 16 E6 among Honduran women. Int J Gynecol Cancer Off J Int Gynecol Cancer Soc. 2010;20:323-8.

37. Xi LF, Koutsky LA, Hildesheim A, Galloway DA, Wheeler CM, Winer RL, et al. Risk for high-grade cervical intraepithelial neoplasia associated with variants of human papillomavirus types 16 and 18. Cancer Epidemiol Biomark Prev Publ Am Assoc Cancer Res Cosponsored Am Soc Prev Oncol. 2007;16:4-10.

38. Méndez-Martínez R, Rivera-Martínez NE, Crabtree-Ramírez B, Sierra-Madero JG, Caro-Vega Y, Galván SC, et al. Multiple human papillomavirus infections are highly prevalent in the anal canal of human immunodeficiency viruspositive men who have sex with men. BMC Infect Dis. 2014;14:671.

39. High prevalence of human papillomavirus type 58 in HIV infected men who have sex with men: A preliminary report in Central Italy - Sammarco - 2016 - Journal of Medical Virology - Wiley Online Library. https://onlinelibrary. wiley.com/doi/full/10.1002/jmv.24406. Accessed 15 Oct 2019.

40. King EM, Oomeer S, Gilson R, Copas A, Beddows S, Soldan K, et al. Oral human papillomavirus infection in men who have sex with men: a systematic review and meta-analysis. PLoS One. 2016;11:e0157976.
41. Natural history of human papillomavirus infections involving anal, penile, and oral sites among HIV-positive men. - PubMed - NCBI. https://www.ncbi. nlm.nih.gov/pubmed/23250297. Accessed 15 Oct 2019.

42. Breese $\mathrm{PL}$, Judson FN, Penley KA, Douglas JM. Anal human papillomavirus infection among homosexual and bisexual men: prevalence of type-specific infection and association with human immunodeficiency virus. Sex Transm Dis. 1995;22:7-14

43. Law CL, Qassim M, Thompson CH, Rose BR, Grace J, Morris BJ, et al. Factors associated with clinical and sub-clinical anal human papillomavirus infection in homosexual men. Genitourin Med. 1991;67:92-8.

44. Mortimer JY, Evans BG, Goldberg DJ. The surveillance of HIV infection and AIDS in the United Kingdom. Commun Dis Rep CDR Rev. 1997;7:R118-20.

45. Piketty C, Darragh TM, Da Costa M, Bruneval P, Heard I, Kazatchkine MD, et al. High prevalence of anal human papillomavirus infection and anal cancer precursors among HIV-infected persons in the absence of anal intercourse. Ann Intern Med. 2003;138:453-9.

46. Syrjänen S. Oral manifestations of human papillomavirus infections. Eur J Oral Sci. 2018;126:49-66.

47. Kero K, Rautava J, Syrjänen K, Grenman S, Syrjänen S. Oral mucosa as a reservoir of human papillomavirus: point prevalence, genotype distribution, and incident infections among males in a 7-year prospective study. Eur Urol. 2012;62:1063-70.

48. Rollo F, Latini A, Pichi B, Colafigli M, Benevolo M, Sinopoli I, et al. Prevalence and determinants of oral infection by human papillomavirus in HIV-infected and uninfected men who have sex with men. PLoS One. 2017;12:e0184623.

49. Pierce Campbell CM, Kreimer AR, Lin H-Y, Fulp W, O'Keefe MT, Ingles DJ, et al. Long-term persistence of oral human papillomavirus type 16: the HPV infection in men (HIM) study. Cancer Prev Res (Phila). 2015;8:190-6.

50. De Vuyst H, Clifford G, Li N, Franceschi S. HPV infection in Europe. Eur J Cancer Oxf Engl. 2009;45:2632-9.

51. Hartwig S, Syrjänen S, Dominiak-Felden G, Brotons M, Castellsagué X. Estimation of the epidemiological burden of human papillomavirus-related cancers and non-malignant diseases in men in Europe: a review. BMC Cancer. 2012;12:30.

52. Donà MG, Palamara G, Di Carlo A, Latini A, Vocaturo A, Benevolo $M$, et al. Prevalence, genotype diversity and determinants of anal HPV infection in HIV-uninfected men having sex with men. J Clin Virol Off Publ Pan Am Soc Clin Virol. 2012;54:185-9.

53. Poizot-Martin I, Henry M, Benhaim S, Obry-Roguet V, Figarella D, Tamalet C. High level of HPV 16 and 18 DNA load in anal swabs from male and female HIV-1 infected patients. J Clin Virol Off Publ Pan Am Soc Clin Virol. 2009:44:314-7.

54. Goldstone S, Palefsky JM, Giuliano AR, Moreira ED, Aranda C, Jessen H, et al. Prevalence of and risk factors for human papillomavirus (HPV) infection among HIV-seronegative men who have sex with men. J Infect Dis. 2011; 203:66-74.

55. Vardas E, Giuliano AR, Goldstone S, Palefsky JM, Moreira ED, Penny ME, et al. External genital human papillomavirus prevalence and associated factors among heterosexual men on 5 continents. J Infect Dis. 2011;203:58-65.

56. Palefsky JM, Giuliano AR, Goldstone S, Moreira ED, Aranda C, Jessen H, et al. HPV vaccine against anal HPV infection and anal intraepithelial neoplasia. N Engl J Med. 2011;365:1576-85.

\section{Publisher's Note}

Springer Nature remains neutral with regard to jurisdictional claims in published maps and institutional affiliations.

Ready to submit your research? Choose BMC and benefit from:

- fast, convenient online submission

- thorough peer review by experienced researchers in your field

- rapid publication on acceptance

- support for research data, including large and complex data types

- gold Open Access which fosters wider collaboration and increased citations

- maximum visibility for your research: over $100 \mathrm{M}$ website views per year

At BMC, research is always in progress.

Learn more biomedcentral.com/submissions 